\title{
Rosa de Santa María
}

\author{
Esteban Puig Tarrats
}

Mucho y bien se ha dicho y escrito de la vida de Santa Rosa de Lima. Uno de los más notorios en hacerlo ha sido el padre jesuita Rubén Vargas Ugarte. ${ }^{1}$ Más cerca de nuestros tiempos, el profesor José Antonio del Busto Duthurburu escribió una maravillosa y completa biografía de nuestra Santa, ${ }^{2}$ con arte y pericia -como nos tiene acostumbrados-, donde enlaza los hechos, sucesos y palabras entresacados en envidiable prodigalidad del Primer Proceso Ordinario para la Canonización de Santa Rosa de Lima (PPOCSRL), ${ }^{3}$ que hacen del relato una delicia de historia y de literatura. Con que gusto se lee. Muchas veces asombran diversos episodios que pueden pasar desapercibidos por los devotos de Santa Rosa. Y con todo, son primorosos y conviene destacarlos. Este es el motivo del presente trabajo.

Por esto y por otros motivos más personales -celebramos los 400 años de su traslado al cielo- he pensado, al escribir este artículo, extraer aquellos episodios más relevantes de su vida y de su alma. Evidentemente que no seré muy prolijo y tendré que dejar para otra ocasión, con bastante sentimiento, varios de ellos.

Ofrezco de todo corazón y como reconocido homenaje a José A. Del Busto, maestro y amigo, mi más sincera gratitud por lo escrito de santa Rosa y espero que en el más allá, en el abrazo de Dios Padre, pida que cuide al Perú y nos apoye en estos desastres naturales que estamos sufriendo, convirtamos el corazón, tengamos limpia el alma, ardoroso el coraje, metidos en Dios, reconstruyendo nuestra Patria a fin de que: "unidos todos como una fuerza hagamos grande nuestro Perú".

Con motivo de celebrarse los 400 años de la muerte de Rosa de Santa María, los peruanos podemos pedir con más fe a nuestra Santa, Patrona de Lima, Patrona del Perú, Patrona de América y Patrona de las islas Filipinas, que no nos niegue su intercesión y sus favores.

\footnotetext{
${ }^{1}$ Utilizo la más reciente edición de La Flor de Lima. Santa Rosa. Lima, Editorial Paulinas, 2013.

2 Santa Rosa de Lima. Lima, Pontificia Universidad Católica del Perú, 2016.

${ }^{3}$ La documentación del proceso ha sido transcrita, anotada y publicada por R. P. Dr. Hernán JimÉnEZ Salas, O.P. en Lima, Edición del Monasterio de Santa Rosa, 1999.
} 
No quiero esposo mío más riquezas, que adorarte, ni otro deseo que servirte.

Santa Rosa de Lima

Santa Rosa de Lima nació el 20 de abril de 1586 y murió en olor de santidad el 24 de agosto de 1617. El arco de su vida abarca 31 años en los cuales se santificó cumpliendo fidelísimamente la voluntad de Dios, manifestada en las obras y sucesos de cada día. La santidad consiste en recibir la gracia de Dios y ser fieles heroicamente en el cumplimiento fiel de su voluntad. Es evidente que: "la acción de Dios, Señor de la Historia, y la corresponsabilidad del hombre en su dramática y fecunda libertad -lo dice el cardenal Tarsicio Bertone-, son los dos goznes sobre los que se construye la historia de la humanidad".

Pasaron 82 años antes que fuera beatificada (declarada beata) por Clemente IX (12 de abril de 1668) y 19 años después de la beatificación, fue canonizada (inscrita en el catálogo de los santos) por Clemente X (12 de abril de 1687). Es la primera mujer nacida en el Perú que sube a los altares.

Lima -religiosa y virreinal- tenía medio siglo de fundada cuando nació Isabel Flores de Oliva que más tarde tomó el hábito de terciaria en la orden dominicana.

La actividad civil estaba marcada por la devoción religiosa. Las torres de las iglesias y conventos sobresalían airosas sobre el perfil urbano. Todo estaba perfectamente estructurado. El doblar de las campanas de la catedral, de las iglesias y conventos servía de reloj, de vigías y de avisos alegres que anunciaban tanto las festividades como los sucesos luctuosos, las tragedias, terremotos, invasiones, y toda clase de peligros como prevención a los ciudadanos. Al toque del alba, a las 6 de la mañana se iniciaban las labores domésticas y manuales. $\mathrm{Al}$ cruzarse en la calle las personas se saludaban "Días de Dios, tengan sus mercedes." A medio día tocaban, después de rezar el ángelus, a recogerse en sus casas para la comida y anuncio de las vísperas. Al cruzarse con otra persona respetable le saludaban: “Tardes de Dios, tenga usted," A las dos y media reinicio de las actividades hasta las seis de la tarde. Se rezaba el ángelus. Nuevamente, al encontrarse las personas salía espontáneo el saludo: "Noches de Dios, tengan su señorías", si éstas eran tales. Los encargados prendían los faroles en las esquinas de las plazas y calles importantes. Antes o después de la cena, se rezaba el rosario en familia. Después de un rato de esparcimiento, se iban a dormir.

La familia en pleno asistía a la misa todos los domingos y fiestas. Se celebraban, también con esplendor y fastuosidad, las fiestas de los santos patrones y, con inusitada solemnidad, las de Navidad, Semana Santa y Corpus Christi, las fiestas de la Inmaculada Concepción y de su Asunción. Las órdenes religiosas competían entre sí sobre cuál de ellas sería la más esplendorosa y más solemne. No faltaban en las procesiones la música de chirimías y vihuelas con 
danzantes vestidos de vivos colores llevando puestas máscaras representando diablos, animales y costumbres ancestrales.

Las clases sociales estaban bien definidas y calificadas según su origen: español, indio, mestizo, zambo, negro... y toda la variedad que el amor humano es capaz de reproducir. Era un mosaico de razas.

Su padre Gaspar Flores fue natural de San Juan de Puerto Rico. Su madre fue María de Oliva y Herrera, "criolla" de Lima. Según otros fue "mestiza". Los hijos de Gaspar Flores y María de Oliva fueron trece. Al primogénito, Gaspar Flores de Oliva, le seguían Bernardina, Hernando, Isabel, Francisco, Juana, Antonio, Andrés, Francisco y Jacinta y algunos más, de los que nada sabemos de ellos, ni sus nombres ni su deceso.

La casa natal de la niña quedaba al oeste de la capital, a un tiro de ballesta de la orilla izquierda del río, abajo del convento de Nuestra Señora del Rosario en la calle que va a las espaldas del [hospital] Espíritu Santo.

Modesta en su estructura y sencilla en su interior como todavía puede apreciarse en algunas casonas de Barrios Altos que aún permanecen inhiestas, aunque se parecen más bien a pordioseros errantes. El vecindario tenía una iglesia y como patrón a san Sebastián, soldado del ejército romano muerto a flechazos por ser cristiano.

Su situación económica era muy precaria, de bajo nivel social pero no del último. De hecho, el padre buscó trabajo como soldado, minero, obrajero, intérprete, profesor de esgrima y maestro de danza. María de Oliva, la madre, solucionaba en parte las necesidades de una familia numerosa, trabajando en labores domésticas como tejedora en bordados, calados, encajes, puntillas y todo conjunto de las maravillas de labores que más tarde enseñó a su hija Rosa, y de las que ella despuntó con primor, finura y belleza hasta tal punto que causaba admiración entre las damas que visitaban a su madre y las amistades que disfrutaban con tales modelos de colores y figuras.

El bautismo de la niña se realizó el 25 de mayo del 1586. En la actual iglesia de San Sebastián se conserva todavía la pila de piedra donde fue bautizada. También en ella, siete años antes que Rosa, fue bautizado San Martín de Porras Velásquez, un 9 de diciembre de 1579.

La madre de Rosa, no podía dar de lactar a su hija ni tenía dinero para alquilar un ama que la criase. Los testigos en el proceso no dejaban de comentar "que esta bendita santa desde sus tiernos años, aún meses, hiciese también actos heroicos de virtud. Pues siendo de edad de nueve meses..., se sustentaba la criatura chupando el dedo pulgar".

Le pusieron por nombre Isabel como un cumplido hacia la abuela materna, Isabel de Herrera, quien halagaba a la niña con particular esmero. La madre le llamó Rosa. Un día, estándola meciendo a la niña en la cuna una india criada, llamada Mariana, al descubrir el velo que tenía en su rostro para saber si ya estaba dormida, vio que "la bendita niña tenía en las mejillas dos rosas

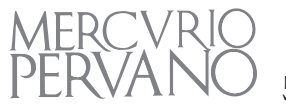


pintadas". Se quedó admirada y llamó a otras dos niñas que allí estaban y al ver el rojo encendido en los pómulos de la niña, saltaron de gozo alborotando toda la casa. La madre al escuchar los gritos se acercó a la cuna donde estaba su hija y al verla así de sonrojada y sonriente, la levantó y llena de contento se decía: "que mientras viviere de su boca no has de oír otro nombre sino el de Rosa". No le gustó mucho a la abuela tal insolencia; sin embargo, testaruda al fin, siguió llamándola "Isabellica" y la madre, por no ser menos, la llamaba "Rosica".

No acabó aquí el asunto de su nombre. La abuela y la madre siguieron en sus trece. Once años mantuvieron sus riñas y peleas e inclusive a Rosita le caían los golpes y castigos inmerecidos. Eran las típicas rencillas familiares entre una mujer con temple de conquistador y una "criolla" limeña. Según se desprende del Proceso, tres testigos afirman que a la madre se le descubre: "activa, hacendosa, preocupada, religiosa, irascible, tenaz, dominante, curiosa, efusiva y temerosa de oscuridades". Entonces, no es vana la retahíla de calificativos y el primor de sugestivos adjetivos. A tanto llegaba la duda y la angustia de Rosa, ya muchacha, de si llamarse Isabel como quería la abuela o llamarse Rosa como pregonaba su madre, buscó consejo en su confesor. Este, buen director y de buen criterio, le dijo que su obligación era obedecer a su madre antes que a la abuela.

Un relato afirma que santo Toribio de Mogrovejo, arzobispo de la ciudad de los Reyes de Lima, hacia febrero de 1598, al pasar por Quives en su visita pastoral, confirmó a la niña de once años de edad, con el nombre de Rosa de Santa María sin que el arzobispo supiera de antemano, según se dice, tal nombre. Lo curioso del caso es que al confirmarla su madre dijo también que el nombre de su hija era Rosa, haciendo gala de lo que siempre afirmaba.

El hecho aparece anotado por varios biógrafos de la santa. Es evidente que entre el santo prelado y Rosa de Lima, el Espíritu Santo estimuló a los dos con abundancia de gracias y bendiciones y que fue santo Toribio quien le impuso el nombre de Rosa de Santa María. De hecho, santa Rosa pudo haber visto e incluso dialogado con santo Toribio, pues desde su confirmación ocurrida en el año 1598 hasta la muerte del santo arzobispo (acaecida en el año 1606, en la villa de Santiago de Miraflores de Saña), pasaron 8 años.

Rosa se trasladó a vivir en Lima a los 26 años con la familia de don Gonzalo de la Maza, por tanto hasta la muerte de santo Toribio pasaron 4 años en los que bien pudo Rosa departir con el santo arzobispo sus confidencias y aprender de él su amor y dedicación por los negros esclavos a quienes el señor arzobispo prohibía llamarles negros, sino que debían ser llamados "morenos" o bien por sus nombres de pila.

En el convento de Santa Clara de Lima, fundado por el santo obispo, quiso dejar a su muerte su corazón. Con sus manos trasladaba los adobes ayudando a levantar las paredes. Todavía hoy día se muestra la ventana con dos asientos de piedra donde, se dice, platicaba el santo arzobispo con Rosa. 
El encuentro entre esos dos santos del Perú, pronto despertó una fuerte y sensible devoción. Es explicable el orgullo y afán de los devotos de santa Rosa de vanagloriarse, y que una santa peruana fuera confirmada por un santo arzobispo, nada menos que santo Toribio infatigable pastor, padre de los pobres, maestro, protector de los negros, organizador de la iglesia peruana y regente de la Arquidiócesis de Lima, resultaba, por sí solo, una delicada y maravillosa acción de Dios en bien del Perú. De hecho, la Iglesia de Perú cuenta con cinco peruanos canonizados, contemporáneos y vecinos en la ciudad virreinal: santa Rosa de Lima, san Martín de Porras, san Juan Macías, san Francisco Solano y santo Toribio de Mogrovejo. Constituye un hecho único en toda la Iglesia, ocurrido solo en los primeros siglos del cristianismo, y sorprende que, a los 35 años de la evangelización fundante, el Perú tuviera ya cinco santos. ¡Y qué santos!

En cierta ocasión se vio rodeada de rosas y se preguntaba qué sería aquello. Entonces se le apareció la Virgen María llevando al Niño Jesús en sus brazos, quien le decía que recogiera las rosas. Así lo hizo. El divino Infante, tomando una de ellas, se la dio diciendo: "Esta Rosa eres tú: de ella se encarga con especial cuidado mi Providencia. De las demás dispón como te agrade", en clara alusión al deseo que tenía Rosa de fundar un convento en honor de santa Catalina de Siena a quien Rosa la tenía por modelo y maestra de su vida interior.

Estando un día rezando en la capilla del Rosario de la Iglesia de Santo Domingo de Lima, ante la imagen de la Virgen María con el Niño, "con el afecto que la estaba mirando, vio que la Reina de los Ángeles "muy encendida y muy alegre" miraba el rostro de su Hijo y que luego el divino Infante volvió a mirarla a ella, también con el rostro muy alegre, y le dijo: "Rosa de mi corazón, sé mi esposa". Y ella con esta gran merced se había humillado delante de su Señor y le respondió: "Sí quiero, Señor".

Le contaba un día santa Rosa a fray Luis de Bilbao que una noche vio en sueños muchas rosas esparcidas en el suelo sin orden y apareciéndosele Cristo le dijo: "Rosa de Santa María, esposa mía, levántate y en esta cestita recoge estas rosas y de ellas hazme una guirnalda". Levantándose tejió una corona que, amorosamente, puso en la cabeza del Salvador, desvaneciéndose la visión.

¡Oh si conociesen los mortales
qué gran cosa es la gracia y
qué hermosa, qué noble,
cuántas riquezas esconde en sí,
soros, cuántos júbilos y delicias!

Santa Rosa de Lima

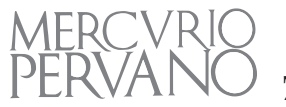


Rosa, a los 15 o 16 años de edad era ya una doncelluela. La madre, siempre solícita, cuidaba con esmero: "cabello, rostro y vestidos" de su hija. Deseaba que su hija estuviera bien presentada. En cuanto al cabello procuraba que fuera rubio. La sometía a mil enjuagues, pócimas y teñidos. Obedeciendo en eso y en todo a su madre, a Rosa no le gustaba tanta frivolidad y esmero en obtener la apariencia de una señorita acicalada como las muchachas de clase alta. La disgustaba tanto boato. Optó por una solución: tomó la tijera, se encerró en una habitación y al salir, a la madre casi le da un vahído: "¡se había cortado su hermosa cabellera rubia!" La madre montó en cólera. Hubo gritos y castigos, pero la hija continuó sin su cabellera dorada. Probablemente, desde ahí, usaría cofia o toca.

Se la miraba con gusto, cautivaba sin maldad y se la admiraba por su candor. $\mathrm{Su}$ rostro blanco y de mejillas encarnadas, arrancaba elogios. Unas señoras que visitaban a su madre, al ver tan hermosa, graciosa y gentil doncella le pidieron que le confeccionara una guirnalda de rosas y se la pusiera en la frente para que resaltara aún más la belleza de su rostro. Cuando tuvo de 18 a 20 años era ya una doncelleja y su madre pronto actuó de casamentera y esperaba casar a su hija con un buen marido de familia noble y, a ser posible, atractivo, de buena posición social. De ahí que la vestía de sedas y pañoletas, guantes de piel de buitre y mantones.

Rosa intentaba por todos los medios deformar su figura. Al amparo de Mariana, la sirvienta de la casa, le ayudaba en sus lances en mortificar su cuerpo y sentidos. Afligía el cuerpo con ayuno y cilicios, usaba baños fríos en pleno invierno. Ante el elogio de sus manos -finas y delicadas-, las metió dentro de cal viva para desfigurarlas pues la finura y delicadeza de las manos era un distintivo mujeril de mucho encanto. Se frotó, ante el espanto de su madre, los ojos con ají para deformar su rostro... En vano. Por mucho que intentó toda clase de industrias cosméticas, en ajar y marchitar su rostro, no consiguió por entero su intento y todavía en los últimos años de su vida conservaba la belleza de sus facciones.

Nuestra Flor de Lima, en la época de su juventud, prácticamente se refugió en su hogar. Salía solo para asistir a Misa y visitar, por breves momentos, a amigas de su madre. Su casa se convertía en un pequeño taller. Trabajaba como costurera. Bordaba con primor. Damas, amigas, cofradías solicitaban sus servicios.

En cierta ocasión pidió a su madre -era el tiempo que vivía largos ratos en su "ermita"- que le dejara ponerse el hábito de san Francisco. Era muy común en aquel entonces que los miembros laicos de ciertas cofradías usaran en las festividades de sus patronos o en fechas memorables, el hábito pertinente. Su madre, se lo negó. Acudió a su padre -que estaba enfermo- solicitándole que le permitiera usar el hábito marrón con el cordón blanco, distintivo de los franciscanos. Este le dijo que no tenía dinero para ello. Ni corta ni perezosa, Rosa, con este tesón que le caracterizaba, se fue a un comercio de telas, compró la tela deseada y ella misma se confeccionó el sayal. Su madre no le dijo nada. 
La placidez interior de la casa y el runrún de las costureras se veía superado por el canto de Rosa, que tenía una voz tan bonita que daba envidia. A veces se acompañaba con la vihuela, que tocaba con singular maestría. Un día, al prender fuego con un tizón, escuchó los trinos melodiosos de un pajarito. Se quedó enajenada, pasmada, estática. Cuando volvió en sí, se dio cuenta que el leño, después de tanto rato encendido, se había incinerado totalmente. A ella le pareció que el suceso fue cosa de un instante, pero, en realidad estuvo así un rato larguísimo.

La gracia va acompañada de la cruz.

Santa Rosa de Lima

Los santos -lo mismo debería suceder a todos los cristianos-, a medida que van conociendo y se dejan amar de Dios, se identifican con todo lo de Dios: el amor, la atención inmediata a un niño que llora, la deliceza de dar una flor en el día del cumpleaños, saber dar gracias por un favor recibido, sonreír, esa conmoción del alma al saber que Él ama siempre. Al sentirse amados, experimentan una sorprendente afinidad entre el Creador y las criaturas. Saben contemplar porque tienen la capacidad de admirarse ante la belleza de las cosas creadas. Rosa sabía ver en las cosas la presencia amorosa del Creador y su Providencia porque sabía pasar limpiamente de lo que veía en las cosas pasar a Dios, Belleza absoluta.

Amaba las flores y se pasaba largos ratos de noche contemplando el cielo tachonado de estrellas con la luna parecida a una medalla de plata colgada como una lámpara votiva entre miríadas de estrellitas parpadeando, jugando a su alrededor. Cuidaba las flores y dedicaba tiempo a las macetas de su jardín exuberantes de rosas, jazmines, alelíes, cucardas...

Cuentan el suceso que tuvo con su amado Jesús sobre un maceta con una mata de albahaca a la que tenía especial afecto. Se ha desfigurado el suceso, pero la piedad popular es asombrosamente insistente. Lo menciono a fin de señalar el afecto y cuidado que sentía por las flores. Una mañana se encontró con el tiesto roto a pedazos y la planta de albahaca marchita, caída en el suelo. Se llevó un disgusto enorme, casi rompe, también, a llorar. Al retirarse, dicen, vio con los ojos del alma a Jesucristo que le reprochaba por tener más amor a una planta que a Él.

Si revisamos algunas de las pinturas que se hicieron de los hechos y sucesos de santa Rosa, sobre todo los realizados por maestros pintores, escultores y artistas después de su beatificación, en los siglos XVII y XVIII, encontraremos por qué plasman estas escenas devotas algo desfasadas de la realidad. La religiosidad popular o la piedad popular, que así también se llaman, "significa que la fe está arraigada en el corazón de todos los pueblos de modo que se introduce en la esfera de lo cotidiano". Son palabras magistrales de Joseph Ratzinger. Ciertamente la

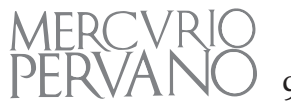


religiosidad es "la primera y fundamental forma de inculturación de la fe, que debe dejarse orientar y guiar continuamente por las indicaciones de la liturgia, pero que a su vez fecunda la fe a partir del corazón". El quehacer cotidiano, lo común, el pueblo lo tiene siempre a la vista, pero lo espectacular, lo sorprendente, lo maravilloso que más apreciaba el devoto donante al encargar la pintura de la Santa, era el sello divino, la señal evidente del hecho que le pintura transmite.

¿Por qué aparecen en la imagen de Santa Rosa objetos distintivos, propios de Santa Rosa como la guirnalda, la corona de fierro, el áncora, corazones alados y lemas escritos a su alrededor? ${ }^{4}$ Dos características sobresalen: la primera, lo referente a su figura y atuendo. La segunda, las escenas de los sucesos espectaculares y maravillosos que la Santa realizó o se le atribuyeron.

En primer lugar, resulta significativo que se le muestra con dos "símbolos del criollismo limeño virreinal". En una mano, santa Rosa sostiene Lima sobre un ancla, y en la otra, el Niño entre flores y olivas, una alusión velada a los nombres de sus padres o a su origen criollo; viste el hábito dominico y toca franciscana. Le distinguen la cruz pectoral, el rosario, el anillo, la guirnalda de rosas, el ancla, la ermita y el pozo del huerto. Cuando se aparece la Santísima Virgen María con el Niño Jesús, éste le ofrece una rosa o, con la aguja enhebrada, que enseña, sonriente, está a punto de ayudarla graciosamente a coser.

Me detendré en un signo que a muchos llama la atención. En algunas pinturas aparece santa Rosa con un ancla grande. ¿Por qué esta ancla si ella no fue marinera ni es la patrona de la Marina?

Piratas ingleses y holandeses y aún franceses subvencionados por los reyes y príncipes de sus países, buscaban el flujo de los metales que salían de las minas de Potosí del Perú desde el Callao rumbo a España. Eran corsarios y piratas que no temían ni a Dios ni a nadie. Con barcos ligeros, asaltaban a los buques españoles en plena mar y se llevaban el botín. Bloqueaban los puertos, saqueaban las poblaciones quemando sus viviendas de madera. Los bucaneros, conocedores de las riquezas del oro y de la plata del Perú, su magnificencia, su ostentación y el lujo de los limeños tanto seculares como religiosos, se les abría el apetito ante las riquezas y bienes que la ciudad de los Reyes brindaba.

El corsario holandés Joris van Spielbergen quiso asaltar el puerto del Callao y saquear la ciudad de Lima. Echó anclas en el pequeño pueblo de Cerro Azul en el corregimiento de Cañete. Su presa favorita era Lima. Al poco tiempo, Spielbergen desplegó sus velas y enrumbó hacia el puerto del Callao. El 21 de julio de 1615, a las 3 de la tarde, entró en el puerto. Lima se puso en pie de guerra. Tres mil hombres apostados en la playa estaban listos a impedir el desembarco. Rosa sacó su fuerza y valentía. Con un grupo de mujeres que la seguía, les esperaba en la iglesia de Santo Domingo ante el altar mayor donde estaba el

\footnotetext{
${ }^{4}$ Sigo en parte las descripciones ofrecidas por José Flores ArÁoz y otros, Santa Rosa y su tiempo. Lima, Banco de Crédito del Perú, 1995.
} 
Santísimo expuesto para defender, aun a costa de su vida, que no se profanara el augusto sacramento. Su madre acudió presurosa y nerviosa. Al ver que su hija "se había quitado los chapines y que se estaba alzando y acortando el hábito", le preguntó: "Pero hija ¿para qué haces eso?" Y contestó Rosa: "Porque dicen que los frailes han entrado a tomar armas, por estar los enemigos en el puerto; que se teme que van a saltar en tierra y venir acá, y si vienen, madre mía, me tengo de subir al altar mayor, donde estaba el Señor descubierto, y con este rosario, los tengo de rendir a todos".

Heroína, genio de mujer. De hecho, los corsarios holandeses no desembarcaron, levaron anclas y desaparecieron en la bruma del horizonte. Se había salvado Lima gracias al coraje y a las oraciones de Rosa de Santa María. De ahí el ancla que ostenta en las pinturas y que se la tenga como la heroína que salvó Lima.

Una escena simpatiquísima: Rosa tenía un dolor de garganta muy fuerte. Se le aparece Jesús con un par de dados para echarle una "partidita". Se dice que a la primera tirada, lo ganó Rosa y desaparecieron los dolores, la segunda lo ganó Jesús y los dolores regresaron. Otra escena pictórica: un perro negro la muerde, el hábito blanco queda manchado de sangre y dos demonios feísimos la golpean rabiosos. Más: Rosa rechaza a un pretendiente, siendo castigada por su madre; Santa Rosa enfermera; Rosa disciplinándose ante una imagen de Cristo, arrodillada, apoyándose en el lecho construido de barbacoas; pétalos de rosas que, al arrojarlas Santa Rosa al aire, formaron un círculo con ellos y dentro una cruz de rosas también.

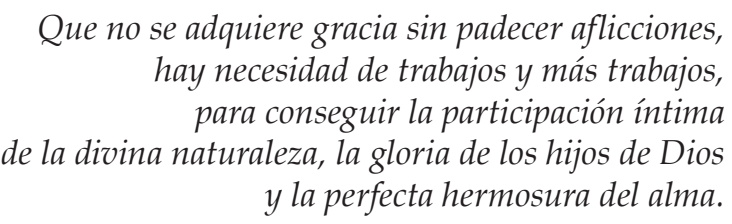

Santa Rosa de Lima

Rosa trabajaba cara a Dios y con sus labores procuraba socorrer a su familia pues los recursos no eran que digamos ni hacederos ni suficientes. Eran muchos hermanos y los padres padecían de varias enfermedades y dolores "que con ganar (...) a la labor de sus manos, muchos reales, trabajando de noche y de día, se los daba a su madre para las necesidades de casa, porque era grande, sobre manera, el deseo que tenía de regalar, servir y honrar, y particularmente en muchas enfermedades, largas y peligrosas que los dicho sus padres tuvieron".

Ahí va otro ejemplo, más inverosímil que los anteriores. La madre cuidaba un pajarito esperando que cantara. Al darse cuenta que era inútil, determinó matarlo. Se enteró Rosa y compadecida del animalito le obligaba a que cantara

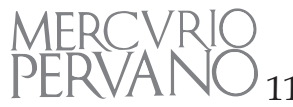


porque, de lo contrario, moriría. Y el pajarito cantó como si estuviera cantando al alba y se salvó de morir.

Los mosquitos fueron otros de los que bien que obedecían a la voz de Rosita. Rosa de Santa María deseaba vivir en soledad. En la huerta de la casa, buscó refugio para aislarse del ruido de sus hermanos juguetones y de alguna que otra visita que le hacían perder el tiempo. En un rincón de la huerta levantó un altarcito, una cajuela más bien de estas que los "limosneros" con una imagen de su patrón o patrona, recorren de pueblo en pueblo, recaudando dinero a favor de los socios enfermos y necesitados. La depositó en su diminuta "ermita" de adobes, levantada con sus propias manos y "tan estrecha que no cabía en ella otra cosa más que su cuerpo". Una "esterilla" clavada en la pared y una "sillita" era todo su ajuar. Allí pasaba muchas horas del día y de la noche orando y meditando para mejor hablar con Dios. Al cerrar la noche, cuando se recogía en su ermita para rezar sus oraciones, entraban en ella una gran cantidad de mosquitos. Rosa hizo un pacto con ellos. Que no le picaran sino, por el contrario, le ayudaran a alabar a Dios al despertarse en la mañana. Cuando se levantaba, abría la puerta y les invitaba a alabar a Dios Nuestro Señor: "me parece que los mosquitos lo hacen con concierto", decía a su confesor.

Junto a la ermita había un pozo que abastecía de agua a los de la casa. Con el correr de los años, la gente dio en decir que sus aguas eran medicinales y milagrosas. Rosa llevaba una cadena penitencial apretada al cuerpo fuertemente. Los dos extremos de la cadena se cerraban con un candado. Un día por prudencia, ante una enfermedad dolorosísima -en la ijada-, quiso quitarse la cadena y al no encontrar la llave, con una piedra rompió el candado y arrojó luego la llave al pozo. En realidad -como escribe acertadamente José Antonio del Busto-, lo que sucedió es que Rosa entregó la llave al dominico fray Antonio Altamirano. "Lo de la llave arrojada al pozo -continúa Del Busto-, lejos de ser verdad, no pasó de ser un fruto de la imaginación popular". No echó Rosa la llave al pozo. La verdad histórica esclarece la leyenda. Aún hoy día en especial, el 30 de agosto, festividad de Santa Rosa, la gente acude en masa a echar el papelito en el pozo de santa Rosa y, por cierto, con fe. Y consiguen los favores.

\section{Cuando servimos a los pobres y a los enfermos servimos a Jesús. \\ No debemos dejar de ayudar a nuestros vecinos porque en ellos servimos a Jesús.}

Santa Rosa de Lima

Rosa, desde muy niña empezó a sentir la presencia de Dios en su alma. El Espíritu Santo iba modelando su vida interior. Oración, mortificación, servicio amoroso a todos. A las almas que el Señor quiere santificar les envía 
enfermedades, pues así les hace participar de su cruz, de ahí que cuando el amor se quiebra por el pecado, el dolor aparece. Por eso se dice que el amor y el dolor son dos caras de la misma moneda.

Ella empezó a experimentar la enfermedad y el dolor desde los cinco años. No deja de ser sorprendente que Dios hiciera partícipe de tanto sufrimiento a una niña de esta edad cuando lo común es que se conozca y entienda el dolor cuando se juzga tener ya uso de razón.

ElSeñor la probó con varias enfermedades. La primera que se tiene referencia es la tiña (hongos en la piel, en la cabeza y también en las uñas), mal que tuvo a los cinco o seis años de edad. La curaba su madre que le echaba en la cabeza "cosas muy fuertes que le ocasionó escoriaciones y una llaga muy grande". Llegó a tener la cabeza tan lastimada que se tuvo que llamar a un cirujano..., lavándole las heridas con vino y piedra lipis, ${ }^{5}$ echándole también alumbre quemado en polvo". En un mes y medio se curó. A pesar del dolor intenso que sufriría, Rosa no se quejó nunca, antes bien, pedía cantando al Señor que le diese más y más dolores y paciencia con ellos. La peor dolencia fue el dolor de ijada, (dolor intenso por debajo de las costillas y por encima de la cadera) mal que sufrió de por vida, pues reaparecía "todos los meses de todos los años [...] hasta que murió".

Sin embargo, a pesar de todo, no se preocupaba tanto de sus enfermedades, sino que se daba íntegra al cuidado y amor a los demás. Cuando sabía del algunos de ellos, los traía a la casa de sus benefactores, el contador Gonzalo de la Maza y su esposa doña María de Uzátegui, donde vivía Rosa. Fueran negros, mulatos, indios pobres y necesitados y de enfermedades asquerosas, los curaba con gran afecto y dedicación. Con razón la llamaban "protectora de los esclavos". Un día curaba a una negra que simulaba estar bautizada para que no la llamaran bozal. Al enterarse Rosa, consiguió que se bautizara. Al día siguiente moría. Rosa estuvo muy contenta de haber logrado que se bautizara. No faltó el caso de un niño "indiecillo" de doce años, con una herida en la nariz causada por la mordedura de un perro. Le dejó el rostro horroroso y desfigurado. Despedía un olor fétido insoportable y el pus hediondo iba subiendo al cerebro. Los médicos y cirujanos lo desahuciaron. Santa Rosa, conmovida, pidió que lo mandaran "a su casa que ella lo curaría y se lo llevaron y dentro de tres días le dio bueno y sano". No era enfermera, pero su dedicación y cuidados eran tan exquisitos que los enfermos confiaban plenamente en ella. Apagaba el dolor humano y encendía el amor divino.

Esta solicitud y dedicación, en especial, por los negros, lo aprendió de santo Toribio de Mogrovejo. Rosa conocía bien las atenciones que el santo Arzobispo de la ciudad de los Reyes de Lima dispensaba a los negros. Cuando llegaban al puerto del Callao, después de una travesía espantosa, los enfermos eran llevados

\footnotetext{
${ }^{5}$ Vítrido azul. Sulfato de cobre.
}

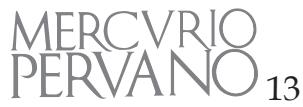


al hospital para su curación. Los negros vivían en el cercado de Lima en galpones y formando grupos. Santo Toribio creó una parroquia y asignó un capellán en ella para que los catequizara, bautizara y administrara los sacramentos. Santa Rosa tuvo los mismos sentimientos. Pudo enterarse de lo que se comentaba en los corrillos de damas, comadres y la gente de los barrios altos de la ciudad. Referían que santo Toribio enfermó en la villa de Santiago de Miraflores de Zaña, y que herido de muerte, lo acomodaron en el aposento de la casa parroquial y allí murió el día Jueves Santo a las tres de la tarde, el 23 de marzo de 1606. La mujer que le preparaba las hierbas y medicinas era una morena. Acompañaban a enterrar al difunto, seis morenos que sostenían cada uno una cinta blanca sujeta al ataúd y los músicos que acompañaban el sepelio eran negros de Lambayeque.

Aparte de la cruz, no hay otra escalera por la que podamos llegar al cielo.

Santa Rosa de Lima

Además de sus oraciones y actos de penitencia, Rosa empezó una etapa de darse a amar, de sufrir y de vivir en continua mortificación. Sólo basta explicar cómo era la primera cama que usó. Del Busto señala que las camas de la Santa, una era de troncos, la otra de teja y las almohadas dignas de tal colchón, pues una era "un adobe" y "una piedra". Sólo a Santa Rosa, considerada como era, se le podían ocurrir tales exquisiteces.

Al ver, de soslayo, estos instrumentos de penitencia tan crueles, uno no sabe qué hacer, si asombrarse o llorar. La cama de troncos constaba de uno largo y dos más cortos transversales sobre una tarima. Sigue Del Busto: "Rosa se echaba sobre el tronco mayor que tenía en su parte superior extrema la oquedad para la cabeza, la cintura en un tronco menor y los pies en el otro". La almohada era un trozo de tronco de pacay con un hueco donde ponía la cabeza. Rosa tenía buen cuidado al levantarse, en esconder los troncos y dejar la tarima de la barbacoa tendida y bien puesta cubierta con una manta y frazada para que su madre no notara nada. Sin embargo, cuando un día descubrió el engaño, montó en cólera y vociferando obligó a su hija pasar a otra cama. Parece que la madre poco conocía del talante de su hija a la hora de sus penitencias. Su hija se mantuvo en sus trece, cambiando de táctica.

En la cama de tejas, así llamada por los testigos en el proceso de beatificación, la barbacoa y la tarima eran las mismas. Pero Rosa amarró las tablas o cañas gruesas insertando en sus junturas trozos de tejas o de botijos de arcilla. Sumaban más de 260 todas puntiagudas o cortantes. Es de esperar que el sueño no sería muy placentero. Mariana de Oliva, su fiel criada, le ayudó en su 
confección. "Y de esta cama tan rigurosa -decía-, usó muchos años sin que su madre se la quitase". Su madre descubrió que seguía poniendo la cabeza en el hueco del tronco del pacay y se lo quitó. No sabemos si gritando también pues en esto siempre fue muy experta. Le dio para almohada un "cojinillo de cumbi" una tela finísima tejida por los indios y muy apreciada entre los españoles, que era como paño de llama, y le ordenó que lo llenara de lana y durmiera con él. Rosa obedeció a su madre..., pero no lo llenó con lana sino con astillas de madera. Nuevamente su madre, al darse cuenta, le obligó a poner lana. Rosa, no dio su brazo a torcer, erre que erre, entre la lana y la funda colocó un hacecillo de cañas y aunque posaba su rostro en el cumbe "sentía la dureza de las cañuelas".

Rosa aguantaba sin rechistar las curaciones a tal punto que el cirujano y los de la casa estaban asombrados al ver el aguante de Rosa. Ella, no sólo soportaba el dolor si no que cantando le pedía a Jesús que le diese más y más dolores. Cuando tenía 12 o 13 años de edad quedó tullida. Nunca se pudo saber cuál fue la causa de tal enfermedad.

Y Dios, en torno al refrán: "cuando más te quiero, más te aprieto", le dio a gustar la cruz y los sufrimientos. Muy temprano le dio un dolor de costado y sin olvidar de ponerse los cilicios de puntillas de hierros, látigos y disciplinas de espaldas y cintura, la cadena de hierro, la corona de púas que ocultaba en su cabeza, disimulada por la toca..., ni para dormir se los quitaba.

$\mathrm{Al}$ caminar por las calles con su hermano, si veía una o algunas cruces formadas por pajas en el suelo, sin reparar en respetos humanos, se bajaba a borrarlas y desbaratarlas, levantando las pajas que tenían formada la cruz y besándola con gran devoción". Su hermano le decía que tal actitud era indecorosa para una doncella pues la podían tomar por extravagante o loca. Le respondió Rosa que lo que le dolía era ver la falta de respeto de los transeúntes que pisoteaban la cruz de Cristo.

No quiero esposo mío más riquezas, que adorarte, ni otro deseo que servirte.

Santa Rosa de Lima

El Espíritu Santo llevó a santa Rosa por caminos de oración y de unión donde el alma se inmersa en Dios y contempla con más clarividencia sus atributos y gracias sobrenaturales. La contemplación -posible en la acción y en el diálogo- es una simple intuición de la verdad que termina en un movimiento afectivo (Santo Tomás), es amorosa y simple atención del espíritu (San Francisco de Sales), es ciencia de amor (San Juan de la Cruz). ${ }^{6}$ Definen estos autores que el

\footnotetext{
${ }^{6}$ Julián Herranz, Atajos del silencio. Madrid, Rialp, 1995, p. 142.
}

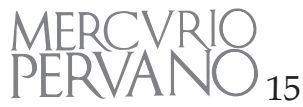


alma por la gracia divina y la cooperación del hombre -se entiende también de la mujer-, se eleva a alturas místicas insospechadas. Amar porque Dios es amor y el amor es digno de fe. "No lo he aprendido de los libros -repetía Santa Rosa-, sino de Dios". Se dejó guiar por Él y así se encontró con el Amor de los amores.

Nuestra santa limeña aprovechaba al máximo el tiempo "en su labor de curiosidades de manos, o en la oración o en la lección de libros devotos". Los libros piadosos llegaban de España o salían de la imprenta de Lima. Le conseguían libros. No sabemos cuántos, no muchos porque el trabajo y sus largas horas de oración no la dejaban ni respirar. Si revisáramos la literatura religiosa, moral y mística que atestaban los anaqueles de las bibliotecas conventuales, podríamos deducir algunos de los que estaban en boga y se leían con fruición. Sabemos, sí, que daba lectura a autores místicos y muy en especial, a fray Luis de Granada, con su famosísima Guía de pecadores (1567). También el Libro de la oración y meditación (1556), que fascinaba a Santa Rosa, y el Memorial de la vida cristiana (1572). Todos del mismo autor. Y paramos de contar.

Rosa de Santa María aprendió a leer y a escribir desde muy pequeña. Escribía cartas y algún que otro librito, por desgracia, hoy desaparecidos. Sin embargo, se conservan dos textos originales de la santa: Las Mercedes y la Escala Mística con dibujos de su mano y pluma. ${ }^{7}$ Rosa nos habla de sus "cuadernos", que serían cuadernos o cuadernillos sueltos. Serían varios cuadernillos en un solo cuerpo o legajo.

También sabemos que a Rosa le encantaba componer letrillas y cantarlas acompañándose con la vihuela. El canto es la más alta expresión del afecto y cariño. Se canta porque con el canto, la danza, la música, alegran el corazón. No es suficiente expresar el amor sólo con palabras. También el cuerpo, sus sentidos y el espíritu, son expresiones del amor y del gozo.

Nuevamente, en el siguiente relato, la piedad popular, conmocionada de afecto, ofusca o tergiversa la realidad histórica. Sin embargo, no se piense que todos los sucesos de su vida son así como han insinuado algunos psicólogos, ya que muchos de los sucesos son auténticas visiones que hay que valorar y aceptar.

Se dice que, en los atardeceres, cuando Rosa entraba en su huerto para entregarse a la oración, entraba un pajarito a posarse en una rama del árbol que había junto a su "ermita" despidiendo con sus trinos el día. La Santa se quedaba encandilada y compitiendo con el pajarito, cantaba esta copla compuesta por ella: "Pajarito ruiseñor: / alabemos al Señor, / alaba tú al Creador / y yo a mi señor".

El canto y la música embelesada a sus oyentes. Una de sus coplas fue muy popular: "Ay, Jesús de mi alma / qué bien pareces / entre rosas y flores / y olivas verdes", haciendo un juego de palabras con las de su nombre y apellidos. Va una letrilla a su Ángel de la Guarda a quien tenía una particular devoción: "Joven

\footnotetext{
${ }^{7}$ Los ha estudiado primorosamente la profesora Rosa CARRASCO LIGARDA, Escritos de Santa Rosa. Lima, Ediciones San Pablo, 2017.
} 
celestial / vuela al Criador / dile que sin vida / yo viviendo estoy... Ruégale que venga / hacia mí veloz / muéstreme tu rostro / que muero de amor".

Conocía los cantares clásicos que los españoles entonaban en sus tiempos de ocio, aunque con ciertos cambios que el lugar y las circunstancias justificaban: "Las doce han dado / y mi amor no viene / ¿quién será la dichosa / que lo entretiene?" (Lope de Vega). Y nuestra poetisa replica: "Ay de mi a mi amante, / ¿quién le suspende? / Ya llega el al medio día / y no aparece. / Mientras en otra parte / sin mí lo pasa, / corazón, alma y vida / se me desmayan".

Doy un resumen de los signos y figuras que aparecen en la iconografía de santa Rosa. Las almas simples y puras fácilmente se elevan a la contemplación donde perciben más íntimamente el don de la belleza, es decir el Amor más acendrado y puro. Los dibujos de Las Mercedes, Mercedes del alma, Heridas del alma o los Favores fueron hechos por Rosa con color rojo tenue, casi naranja, representan verticalmente tres corazones, cada uno signado con una cruz latina, cruz del calvario o cruz de la Pasión. Los dos primeros corazones son de igual tamaño; el tercero es algo mayor.

El primer corazón, el más alto, encierra por completo, y orillando el corazón se encuentra la frase: "Primera merced de heridas que recibí" y así sigue señalando y dibujando diversos signos y emblemas con frases alusivas a su alrededor o "abrasándome" los costados. El primer corazón: cruz latina, ostenta la frase arriba anotada; lanza de acero; una herida en la parte superior. El segundo corazón: cruz latina; en el centro una imagen muy bella del Niño Jesús, sedente en actitud de bendecir. La frase orillada dice: "Aquí descansó Jesús abrasándome el corazón". El tercer corazón: cruz latina; la frase: "El campo del corazón lo llenó Dios de suave amor haciendo morada de él". Este corazón tiene cuatro pequeñas alas de ave.

Para conseguir la santidad hay que ser fiel a los compromisos de amor que todo cristiano tiene con Dios y con los hermanos. Este compromiso exige lucha a diario para crecer en virtudes y rechazar los vicios o pecados. En esta peregrinación de la fe no le faltarán los ataques del demonio -el "mentiroso cósmico"- como lo llamaba san Juan Pablo II, que trata de engañar, seducir y desesperar a la pobre criatura para que abandone y eche por la borda su vida, su amor, su fe. Rosa conocía estas triquiñuelas y argucias diabólicas especialmente los ataques certeros del diablo a quien llamaba con un dejo de humor "el Patón y el Tiñoso".

En esta azarosa peregrinación en la fe el alma se va purificando, se mete más en Dios y con su gracia, la lleva a altas esferas de amor hasta los "desposorios místicos", como le ocurrió a Santa Rosa, y que hemos comentado más al principio cuando vio a la Santísima Virgen María con el Niño que le decía: "Rosa de mi corazón, sé mí esposa".

No hay que olvidar que estas visiones y sucesos místicos no son engaños, ofuscaciones, elevaciones, artimañas ni mucho menos estados patológicos

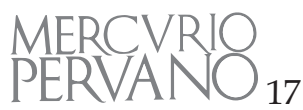


esquizofrénicos, ni neurosis risibles, juegos de magia para ofuscar la fe de la santa. Esos son los ataques de quienes no entienden ni una tilde de la vida cristiana o de la santidad cristiana. ¿Hechos estúpidos, demenciales, cretinos, idiotas...? Tantas cosas infundadas como se han dicho. Todo esto y mucho más les han endosado a los santos y santas. " $\mathrm{OOh}$-escribía santa Rosa-, si conociesen los mortales qué gran cosa es la gracia y qué hermosa, qué noble, qué preciosa, cuántas riquezas esconde en sí, cuántos tesoros, cuántos júbilos y delicias!"

No es de mi incumbencia ahora descifrar el sentido de la visión y los signos que acompañan la figura de Santa Rosa como el ancla, la guirnalda de rosas, el pectoral, el anillo, el rosario que quedaron plasmados en las pinturas del siglo XVIII, después de su beatificación. Se puede consultar en las obras ya mencionadas de José Antonio del Busto y de Rosa Carrasco, para conocer mejor muchos sucesos de la vida de la Santa. También servirá de mucho leer al padre Rubén Vargas Ugarte, en su libro: La flor de Lima, Santa Rosa.

Ya no podía el alma detenerse en la cárcel del cuerpo, sino que se había de romper la prisión y, libre y sola, con más agilidad, debía ir por el mundo, Proclamando el amor de Dios

Santa Rosa de Lima

La Rosa se va deshojando. La muerte estaba anunciada. Rosa cuidaba las niñas de doña María de Uzátegui con su esposo, el contador Gonzalo de la Maza. Rosa se desplomó en la habitación de las niñas. Doña María corrió al cuarto de sus hijas, entró y halló a Rosa caída encima de una tarima. La acomodaron en su cama. Repuesta, doña María de Uzátegui le preguntó: "Hija mía, ¿qué es esto?" Rosa respondió: "Madre mía, morir". A mediados de agosto le vino la hemiplejia. Quedó paralizada de medio cuerpo. Por si fuera poco, le siguió el mal de ijada y un grandísimo dolor.

El jueves 17 de agosto amaneció con un fuerte malestar de gota en el pie derecho y con muy grandes calenturas. Impresionaba ver la paciencia y las oraciones que enviaba a Dios en medio de tantos sufrimientos en tan diversas y contradictorias enfermedades. Dios la puso en el lagar divino para conseguir un caldo -néctar divino- abundante y generoso que alegrara el corazón de sus devotos. Al ver llorar a su madre, Rosa le pidió que no llorara, que las lágrimas eran cosa preciosa, que "no se habían de derramar sino por pecados".

En este tiempo, llamó Rosa a doña María de Uzátegui y le recordó que quería ser amortajada con el hábito de santo Domingo. El lunes 21 de agosto recibió la unción de los enfermos "con grandísima devoción y reverencia". Continuaba Dios exprimiendo a Rosa sin misericordia. Los dolores eran terribles. Con el 
crucifijo entre las manos repetía: “Mi Dios, mi Señor, mi Jesús, mi Esposo y mis amores, dadme dolores".

Ya en los últimos momentos de su vida pidió que vinieran todos los negros y negras esclavos de la casa, hasta los que estaban enfermos " $\mathrm{y}$ a todos juntos pidió con gran humildad, la perdonasen, si en palabra o en obra los había ofendido". Llegaba la hora. Pidió a su hermano Hernando Flores que la acomodara quitando la almohada y reclinó la cabeza en su brazo. Sobrevino el paro cardíaco y exclamó: "Jesús sea conmigo". Y expiró. Era el jueves 24 de agosto de 1617. Como la espiga de trigo llena de granos ubérrimos se inclina por el peso hacia la tierra, así Santa Rosa ya no podía permanecer en la Tierra porque estaba llena de virtudes y amores. El Jardinero divino halló la rosa fresca y olorosa, la cortó y se la llevó consigo al Cielo para siempre. 